\title{
PERENCANAAN RASS KAWASAN PENDIDIKAN RUAS JALAN RAYA KAMPUNG UTAN - SETU CIBUNTU, CIBITUNG -BEKASI
}

\author{
Budiharso Hidayat,MT \\ Dosen STTD \\ Jl. Raya Setu no.89 \\ Cibuntu Cibitung \\ Abadi Sastrodiyoto, $\mathrm{SH}, \mathrm{MH}$ \\ Dosen STTD \\ Jl. Raya Setu no.89 \\ Cibuntu Cibitung \\ Tlp/Fax: ( 021 ) 8254640
}

\author{
Widorisnomo,MT \\ Dosen STTD
}

Jl. Raya Setu no.89

Cibuntu Cibitung

\author{
Subarto,MM \\ Dosen STTD
}

Jl. Raya Setu no.89
Cibuntu Cibitung

Jl. Raya Setu no.89
Cibuntu Cibitung
Drs. Eko Sudriyanto,MM
Dosen STTD

Jl. Raya Setu no.89

Cibuntu Cibitung

Tlp/Fax: ( 021 ) 8254640 Tlp/Fax : ( 021 ) 825464 Tlp/Fax : ( 021 ) 8254640 Tlp/Fax : ( 021 ) 8254640

\author{
F.X Bowo Priyambodo,MT \\ Dosen STTD \\ Jl. Raya Setu no.89 \\ Cibuntu Cibitung \\ Tlp/Fax : ( 021 ) 825464
}

\author{
Sumantri W.Praja, M.Sc \\ Dosen STTD \\ Jl. Raya Setu no.89 \\ Cibuntu Cibitung \\ Tlp/Fax : ( 021 ) 8254640
}

\begin{abstract}
Travel activities to go to school and home school especially for elementary school students is very dominant. Results from preliminary observations indicate that students who were escorted and / or picked up mostly used motorcycles, then used public transport as wella son foot. One of the major cities' transportation problems in Indonesia is safety in traffic. Road user safety is a top priority in traffic management and engineering. Users of this road one of them is a student with the intention of a special trip to learn. Students as the next generation of the nation is expected to survive in order to avoid or become victims of accidents.
\end{abstract}

Keywords: school students, street users, avoid accident

\begin{abstract}
ABSTRAKSI
Kegiatan perjalanan untuk menuju sekolah dan pulang sekolah khususnya bagi siswa Sekolah Dasar sangat dominan. Hasil dari pengamatan awal menunjukkan bahwa siswa yang diantar dan/atau dijemput sebagian besar menggunakan sepeda motor, setelah itu menggunakan angkutan umum serta berjalan kaki.. Salah satu permasalahan transportasi kota-kota besar di Indonesia antara lain adalah keselamatan dalam berlalulintas. Keselamatan pengguna jalan merupakan prioritas utama dalam manajemen dan rekayasa lalu lintas. Pengguna jalan ini salah satu diantaranya adalah siswa dengan maksud perjalanan khusus untuk belajar. Siswa sebagai generasi penerus bangsa diharapkan keberlangsungan agar terhindar atau menjadi korban kecelakaan.
\end{abstract}

Kata Kunci : siswa sekolah, pengguna jalan, terhindar dari kecelakaan 


\section{PENDAHULUAN}

Kegiatan perjalanan untuk menuju sekolah dan pulang sekolah khususnya bagi siswa Sekolah Dasar sangat dominan. Hasil dari pengamatan awal menunjukkan bahwa siswa yang diantar dan/atau dijemput sebagian besar menggunakan sepeda motor, setelah itu menggunakan angkutan umum serta berjalan kaki.

Keselamatan pengguna jalan merupakan prioritas utama dalam manajemen dan rekayasa lalu lintas. Pengguna jalan ini salah satu diantaranya adalah siswa dengan maksud perjalanan khusus untuk belajar. Siswa sebagai generasi penerus bangsa diharapkan keberlangsungan agar terhindar atau menjadi korban kecelakaan.Sepanjang ruas jalan Setu-Kampung Utan yang terletak di wilayah Kecamatan Cibitung dan Setu banyak tersebar sekolah dari taman kanak-kanak sampai perguruan tinggi. Dengan demikian sepanjang ruas jalan ini dapat dilakukan pemilihan lokasi sekolah yang memenuhi syarat dan menarik untuk dilakukan penelitian atau disebut dengan kawasan pendidikan karena banyak terdapat sekolah-sekolah.

\section{Identifikasi Masalah}

Berdasarkan latar belakang yang telah dijelaskan bahwa dapat disimpulkan beberapa permasalahan, diantaranya:

a. Masih banyaknya kendaraan pengantar siswa/i yang berhenti untuk menjemput dan menurunkan di badan jalan (parkir sembarangan), sehingga berdampak pada menurunnya kapasitas jalan, menimbulkan kemacetan dan rawan kecelakaan;

b. Siswa Sekolah Dasar (SD) untuk melakukan perjalanan dari/ke sekolah diantar oleh orang tua dengan membawa kendaraan sendiri, berjalan kaki atau menggunakan angkutan umum belum memiliki fasilitas yang memadai;

c. Pelayanan angkutan umum bagi siswa masih kurang memenuhi aspek keselamatan dalam fasilitas dan sirkulasi pada saat berangkat atau pulang;

d. Lokasi sekolah pada kawasan pendidikan tidak ramah atau tidak berkeselamatan terbukti dengan kondisi fasilitas pejalan kaki yang belum ada di depan sekolah;

\section{A. Pembatasan Masalah}

Penelitian ini membatasi permasalahan pada pembahasan berkaitan dengan perencanaan rute aman selamat sekolah pada kawasan pendidikan terutama yang berhubungan dengan kondisi yang memenuhi syarat untuk diterapkan rute aman selamat sekolah.

Penelitian ini bertujuan : 
1. meningkatkan keamanan dan keselamatan siswa dalam menempuh perjalanan ke dan dari sekolah dengan menyediakan kebutuhan perjalanan ke/dari sekolah untuk masing-masing rute (rute angkutan sekolah, rute sepeda, rute pejalan kaki);

2. menentukan kebutuhan atau fasilitas untuk setiap rute-rute perjalanan ke/dari sekolah baik untuk pejalan kaki, pesepeda, maupun menggunakan angkutan umum;

3. mengurangi penggunaan kendaraan sepeda motor bagi para siswa sekolah;

4. Mendesain kawasan RASS.

\section{Rute Aman Selamat Sekolah (RASS)}

Dalam Peraturan Menteri Nomor 16 Tahun 2016 tentang Rute Aman Selamat Sekolah (RASS) dijelaskan bahwa RASS merupakan bagian dari kegiatan manajemen dan rekayasa lalu lintas berupa penyediaan sarana dan prasarana angkutan dengan pengendalian lalu lintas dan penggunaan jaringan jalan serta penggunaan sarana dan prasarana angkutan sungai dan danau dari lokasi permukiman menuju sekolah.

\section{A. Pengumpulan dan pengolahan data}

\section{Perhitungan Sampel}

Dalam perhitungan sampel digunakan rumus Slovin sebagai berikut :

untuk :

$$
n=\frac{N}{1+N \cdot e^{2}}
$$

$\mathrm{n}=$ Jumlah sampel

$\mathrm{e}=$ Tingkat kesalahan (faktor error) $(\%)$

$\mathrm{N}=$ Jumlah populasi

\section{Penentuan Moda Angkutan Sekolah}

Sebelum perencanaan rute trayek angkutan sekolah terlebih dahulu dilakukan pemilihan moda angkutan. Pemilihan moda ini akan menentukan kelas jalan mana yang layak untuk dijadikan rute trayek angkutan sekolah. Penentuan jenis moda angkutan ini disesuaikan dengan permintaan angkutan sekolah di wilayah studi.

Penentuan jenis angkutan ini berdasarkan klasifikasi trayek dan ukuran kota dari Pedoman Teknik Penyelenggaraan Angkutan Umum di Wilayah Perkotaan Dalam Trayek Tetap dan Teratur, Direktorat Jenderal Perhubungan Darat, Departemen Perhubungan Tahun 2002. 
Tabel 1 Penentuan Jenis Angkutan Berdasarkan Ukuran Kota

\begin{tabular}{|c|c|c|c|c|}
\hline Ukurankc & $\begin{array}{c}\text { Kota Raya } \\
>1.000 .000 \\
\text { Penduduk }\end{array}$ & $\begin{array}{c}\text { Kota besar } \\
500.000-1.000 .000 \\
\text { Penduduk }\end{array}$ & $\begin{array}{c}\text { Kota sedang } \\
100.000-500.000 \\
\text { Penduduk }\end{array}$ & $\begin{array}{l}\text { Kota kecil } \\
<100.000 \\
\text { Penduduk }\end{array}$ \\
\hline Utama & $\begin{array}{l}\text { - } \mathrm{K} . \mathrm{A} \\
\text { - } \mathrm{Bus} \text { besar } \\
\text { (SD/DD) } \\
\end{array}$ & - Bus besar & $\begin{array}{l}\text { - Bus besar' } \\
\text { sedang }\end{array}$ & - Bus sedang \\
\hline Cabang & $\begin{array}{l}\text { - Bus besar/ } \\
\text { sedang }\end{array}$ & - Bus sedang & $\begin{array}{l}\text { - Bus sedang/ } \\
\text { kecil }\end{array}$ & - Bus kecil \\
\hline Ranting & $\begin{array}{l}\text { - Bus sedang/ } \\
\text { kecil }\end{array}$ & - Bus kecil & $\begin{array}{l}\text { - MPU (hanya } \\
\text { roda empat) }\end{array}$ & $\begin{array}{l}\text { - MPU } \\
\text { (hanya roda } \\
\text { empat) }\end{array}$ \\
\hline Langsung & - Bus besar & - Bus besar & - Bus sedang & - Bus sedang \\
\hline
\end{tabular}

Sumber : Surat Keputusan Direktorat Jenderal Nomor 687 Tahun 2002

\section{B. Keselamatan}

Anak memiliki hak untuk mendapatkan perlindungan dari kekerasan dan kecelakaan yang menimbulkan luka/cedera dan kematian. Negara melalui Undang-Undang Dasar Republik Indonesia 1945 pasal 28B ayat (2) menyatakan "Setiap anak berhak atas kelangsungan hidup, tumbuh dan berkembang serta berhak atas perlindungan dari kekerasan dan diskriminasi", dan Undang-Undang Nomor 23 Tahun 2002 tentang Perlindungan Anak, menyatakan bahwa anak memiliki hak untuk mendapatkan perlindungan.

\section{Fasilitas Pejalan Kaki}

Pejalan kaki adalah setiap orang yang berjalan di ruang lalu lintas jalan. Manajemen dan rekayasa lalu lintas salah satunya dengan pemberian prioritas keselamatan dan kenyamanan kepada pejalan kaki. Pejalan kaki berhak atas ketersedian fasilitas pendukung yang berupa trotoar, tempat penyebrangan dan fasilitas lain. Pejalan kaki berhak atas prioritas pada saat menyeberang jalan di tempat penyebrangan. 



Gambar 3.1. Bagan Alir Penelitian 


\section{Pengumpulan Data Primer}

Pengumpulan data primer didapatkan dengan cara melakukan survei langsung di lapangan, data primer tersebut yaitu:

\section{a. Inventarisasi Lokasi Penelitian \\ b. Data Bangkitan dan Karakteristik siswa dan pengantar sekolah. c. Data Volume Kendaraan Terklasifikasi}

\section{Pengumpulan Data Sekunder}

Metode pengumpulan data ini dilakukan dengan cara memperoleh data dari instansi- instansi terkait. Data yang didapat tersebut adalah jumlah siswa pada sekolah yang diteliti.

\section{A. METODE ANALISIS}

Adapun analisis yang digunakan dalam penelitian ini adalah :

1. Analisis Karakteristik Pengunjung sekolah

Analisa terhadap karakteristik pengantar ini dilakukan dengan untuk mengklasifikasikan kategori pengunjung. Pengantar adalah semua orang yang mendatangi sekolah untuk mendampingi siswa.

2. Analisis Titik Lokasi Halte

Penempatan halte disesuaikan dengan posisi bangunan sekolah terhadap jalan yang dilewati angkutan kota/pedesaan anak sekolah. Tempat henti adalah bagian dari perkerasan jalan tertentu yang digunakan sebagai tempat pemberhentian sementara bus, angkutan penumpang umum lainnya pada waktu menaikakan dan menurunkan penumpang.

Perhentian bus adalah lokasi dimana penumpang dapat naik dan turun dari bus, dan juga lokasi dimana bus dapat berhenti untuk menaikkan dan menurunkan penumpang sesuai dengan pengaturan operasional ataupun permintaan penumpang. Jadi, pada dasarnya perhentian bus adalah titiktitik sepanjang lintasan rute dimana pengemudi naik atau turun dari bus.

a. Desain Halte yang Aman

Persyaratan umum tempat perhentian kendaraan penumpang umum dalam Keputusan Direktur Jenderal Perhubungan Darat Nomor 271 Tahun 1996 Tentang Pedoman Teknis Perekayasaan Tempat Pemberhentian Kendaraan Penumpang Umumadalah :

1. Berada di sepanjang rute angkutan umum/bus;

2. Terletak pada jalur pejalan (kaki) dan dekat dengan fasilitas pejalan (kaki);

3. Diarahkan dekat dengan pusat kegiatan atau permukiman;

4. 


\section{ANALISIS DAN PEMBAHASAN}

\section{INVENTARISASI LOKASI PENELITIAN}

Satu-satu ruas jalan yang menjadi akses menuju sekolah ini adalah ruas jalan raya Setu-Kampung Utan. Ruas jalan ini memiliki lebar lajur 3,6 dan 3,9 meter dengan type 2/2 UD. Ruas jalan ini tidak memiliki fasilitas pejalan kaki untuk menyusuri dan median sebagai pembatas jalan. Lebar bahu ruas jalan ini 0,6 meter pada sisi kiri (depan Sekolah Dasar) serta dilengkapi bahu jalan pada salah satu sisi lain (seberang jalan Sekolah Dasar) sebesar 1 meter .

\section{A. KARAKTERISTIK LALU LINTAS}

\section{Volume lalu lintas}

Pencacahan lalu lintas terklasifikasi pada ruas jalan ini dilaksanakan mulai dari jam 05.00 - 22.00 WIB menunjukkan bahwa karakteristik lalu lintas pada lokasi ini saat pagi hari arus lalu lintas menuju Kampung Utan lebih tinggi dibanding menuju Setu. Arus lalu lintas menuju Kampung Utan pagi hari tertinggi mencapai 523 kendaraan/jam dan arah sebaliknya menuju ke Setu sebesar $306 \mathrm{smp} / \mathrm{jam}$.

Kondisi arus lalu lintas pada lokasi hasil pengamatan di ruas jalan raya Setu Kampung Utan atau depan lokasi sekolah dasar 6 dan 7 Cibuntu, Cibitung Bekasi dapat dilihat pada gambar berikut ini.

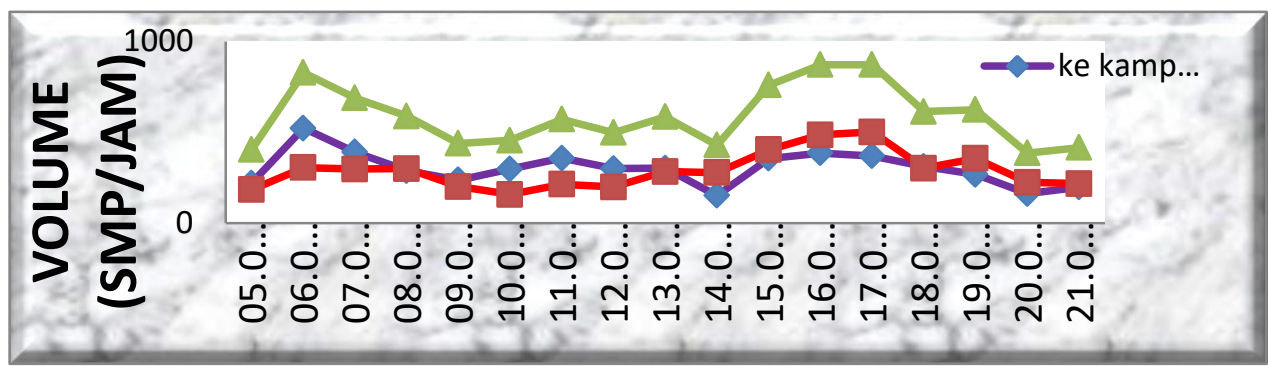

Gambar IV.1. Fluktuasi lalu lintas ruas jalan depan Sekolah Dasar 6 dan 7

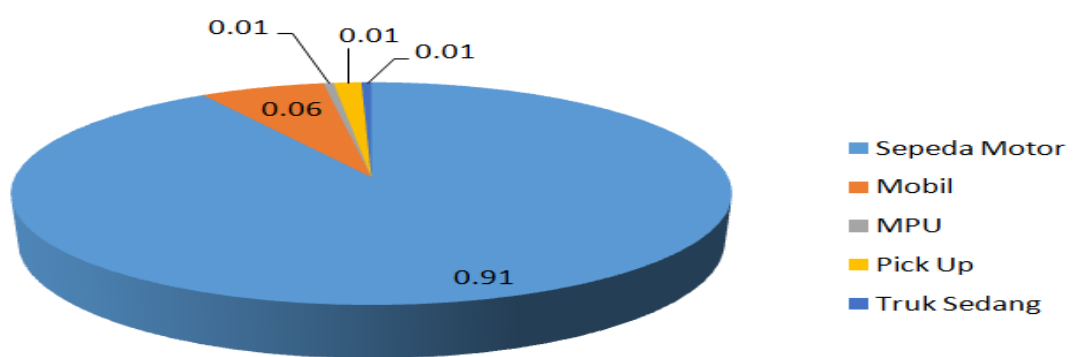

Gambar IV.2. Proporsi penggunaan moda jalan raya Setu-Kampung Utan

Ruas jalan ini merupakan jalan suburban sehingga memiliki pola lalu lintas yang berbeda antar arah, misalnya menuju Kampung Utan pada sore hari lebih tinggi dibanding arah sebaliknya. Proposi penggunaan kendaraan menunjukkan $91 \%$ menggunakan sepeda motor (data dalam bentuk 
kendaraan/unit), sedang moda lain sisanya. Tertinggi kedua adalah kendaraan untuk jenis mobil penumpang $(6 \%)$.

\section{Kecepatan ruas jalan}

Kecepatan arus lalu lintas pada ruas jalan raya Kampung Utan - Setu atau depan Sekolah Dasar 6 dan 7 Cibuntu Cibitung Bekasi memiliki kecepatan sekitar 20,88 km/jam sampai 47,40 km/jam. Kecepatan saat menuju lokasi lebih tinggi disbanding pada saat lokasi pada saat pengamatan pada jam 06.00 - 07.00 WIB. Kendaraan yang menuju Kampung Utan (dari Setu) relatif lebih lambat $(29,41 \mathrm{~km} / \mathrm{jam})$ apabila dibanding arah sebaliknya $(33.43 \mathrm{~km} / \mathrm{jam})$. Pada saat ada aktivitas siswa yang menuju ke sekolah kecepatan kendaraan melambat dari $16,59-17,71 \mathrm{~km} / \mathrm{jam}$ atau relatif lebih lambat dibanding kecepatan kendaraan sebelum sampai di depan sekolah dasar.

Tabel IV.1. Kecepatan kendaraan di ruas jalan Depan SD

\begin{tabular}{|c|c|c|c|c|c|c|}
\hline \multirow[b]{2}{*}{ KONDISI/ ARAH } & \multicolumn{5}{|c|}{ Kecepatan $(\mathbf{k m} / \mathbf{j a m})$} & \multirow{2}{*}{$\begin{array}{l}\text { Rata-rata } \\
\text { (km/jam) }\end{array}$} \\
\hline & $\begin{array}{l}\text { Sepeda } \\
\text { Motor }\end{array}$ & Mobil & MPU & $\begin{array}{l}\text { Pick } \\
\text { Up }\end{array}$ & $\begin{array}{c}\text { Truk } \\
\text { Sedang }\end{array}$ & \\
\hline $\begin{array}{l}\text { Lokasi depan SD } \\
\text { (Ke Kampung Utan) }\end{array}$ & 30.90 & 15.71 & 10.88 & 20.41 & 5.03 & 16.59 \\
\hline $\begin{array}{l}\text { SEBELUM SD } \\
\text { (Ke Kampung Utan) }\end{array}$ & 38.07 & 30.51 & 25.65 & 29.52 & 23.31 & 29.41 \\
\hline Lokasi depan SD (ke Setu) & 33.40 & 19.46 & 11.87 & 15.65 & 8.15 & 17.71 \\
\hline SEBELUM SD (ke Setu) & 45.23 & 33.62 & 28.17 & 33.71 & 26.42 & 33.43 \\
\hline Jumlah & 36.90 & 24.83 & 19.14 & 24.82 & 15.73 & 24.28 \\
\hline
\end{tabular}

\section{B. RUTE AMAN SELAMAT SEKOLAH}

\section{Fasilitas pejalan kaki}

\section{a. Menyusuri}

Permintaan perjalanan untuk sekolah merupakan siswa dan pengantar yang berangkat dan pulang dengan berjalan kaki. Pejalan kaki yang menyusuri sepanjang sisi kiri (seberang ruas jalan) sebesar 33 orang/jam atau 0,56 orang/menit, sedangkan dari sisi kanan (depan sekolah dasar) banyaknya orang yang menyusuri sebesar 31 orang/jam atau 0,53 orang/menit.

\section{b. Menyeberang (ZoSS)}

Penyeberang jalan siswa dan pengantar pada ruas jalan raya Setu Kampung Utan sebesar 35 penyeberang/jam begitu juga sebaliknya pejalan kaki yang menyeberang sebesar 52 penyeberang/jam. Karakteristik penyeberang adalah bergandengan antara pengantar dan siswa sehingga lebar zebra cross yang harus disediakan minimal (1,5 x 2 meter) 3 meter. 


\section{Fasilitas angkutan umum}

Fasilitas angkutan umum ini adalah berupa tempat naik dan turun siswa dan pengantar yang menuju atau meninggalkan sekolah. Type ruas jalan yang terdiri dari dua lajur dua arah sangat rentan dengan gangguan kendaraan yang berhenti. Kondisi ini diperlukan celukan untuk halte bagi tempat perhentian angkutan umum.

Frekuensi kendaraan umum yang melintasi ruas jalan ini dari arah Kampung Utan menuju Setu rata-rata 16 kendaraan/jam dengan penumpang yang turun sebesar 26 orang siswa dan pengantar. Arah sebaliknya frekuensi angkutan umum sebesar 19 kendaraan/jam dengan penumpang yang turun sebesar 23 orang siswa dan pengantar.

Waktu yang diperlukan untuk menurunkan penumpang rata-rata sekitar 3 menit, sehingga kebutuhan ruang untuk frekuensi angkutan umum 16 dan 19 kendaraan/jam sebesar 0,80 dan 0,95 kendaraan. Dengan semikian yang dibutuhkan untuk satu kendaraan angkutan umum berhenti menurunkan atau menaikkan penumpang.

\section{Fasilitas parkir}

Satuan merupakan hal sangat penting untuk diketahui, karena bagaimanapun satuanlah yang digunakan sebagai ukuran atau besarnya sesuatu. Berbagai jenis satuan yang telah digunakan dalam kehidupan sehari-hari, seperti kilogram, meter, ohm, newton dan lain sebagainya.

Begitu juga untuk sistem transportasi juga dikenal berbagai satuan seperti smp, rit, km/jam dan lain-lain. Parkir merupakan salah satu bagian dari sistem transportasi juga tidak terlepas dari satuan. Untuk mengukur kebutuhan ruang parkir, maka satuan yang digunakan adalah satuan ruang parkir (SRP).

Permintaan parkir pada pagi dan sore hari akumulasi parker sebesar 103 kendaraan dan 108 kendaraan. Satuan Ruang Parkir (SRP) untuk sepeda motor ditunjukkan dalam gambar berikut

\section{DISAIN RASS}

\section{a. Fasilitas pejalan kaki}

Fasilitas pejalan kaki terdiri dari :

- Trotoar sepanjang minimal 150 meter dengan lebar 1,5 meter pada kedua sisi $\mathrm{rl}_{70}$; jalan. 70

- Zebra cross dengan lebar 3 meter sepanjang 7 meter (lebar jalan) yang dilengkapi dengan fasilitas ZoSS.

- Fasilitas perlengkapan jalan rambu dan marka yang sesuai. Rambu informasi ZoSS, perintah menyeberang yang banyak anak-anak, 
pemberitahuan awal ada penyeberang jalan, pemasangan warning light. Rambu dan lampu peringatan dipasang dari kedua arah arus lalu lintas. Marka yang diperlukan adalah zebra cross sesuai ZoSS dan pita penggaduh menjelang 30 meter sebelum lokasi zebra cross.

\section{b. Fasilitas angkutan umum}

Fasilitas angkutan umum terdiri dari :

- Halte yang dilengkapi dengan celukan yang dapat menampung satu kendaraan angkutan umum jenis mobil penumpang umum (MPU) dengan panjang 6 meter dan lajur akselerasi sepanjang 6 meter atau dengan total panjang 18 meter. Halte ini dilengkapi dengan fasilitas peneduh.

- Rambu yang diperlukan untuk peringatan adanya halte dan penentuan adanya halte. Marka dibuat sesuai kebutuhan untuk celukan.

- Pada lokasi halte ini diberikan pagar sepanjang 30 meter sebelum area halte.

\section{DAFTAR PUSTAKA}

- 2008, Human Factors For Transport Safety Investigators, Kementrian Perhubungan Darat, Jakarta

- 2009,Undang-undang Nomor 22 Tahun 2009 Tentang Lalu Lintas dan Angkutan Jalan, Direktorat Jenderal Perhubungan Darat, Jakarta

- Barnard, Yvonne, etc, The Safety Of Intelligent Driver Support Systems, Ashgate Publishing Company, USA

- Elvik, Rune, etc, 2009, The Handbook Of Road Safety Measures Second Edition, Emerald Group Publishing Company

- J. Supranto, 2000,Teori dan Aplikasi Statistik, Erlangga, Jakarta

- Notoadmodjo, 2007, Teori Keperilakuan Dalam Pengambilan Keputusan, Erlangga, Jakarta

- Suartana, I Wayan, 2010, Konsep Teori Keperilakuan Transportasi, Andi, Yogyakarta

- Sugiyono, 2011, Metode Penelitian Kuantitatif Kualitatif Dan $R$ \& $D$, Alfabeta, Bandung

- OECD, 2003, Road Safety Impact Of New Technologies, Securite Routiere, OECD Publishing Company 